\title{
SABERES CONSTRUÍdOS PELOS PROFESSORES NAS PRÁTICAS DOCENTES DA EDUCAÇÃO DE PESSOAS JOVENS E ADULTAS (EPJA)
}

\section{KNOWLEDGE CONSTRUCTED BY TEACHERS IN PRACTICE OF EDUCATION OF YOUNG AND ELDERLY PEOPLE (EPJA)}

\author{
Adenilson Souza Cunha Júnior ${ }^{1}$
}

\section{RESUMO}

Esse trabalho, parte compositiva da dissertação de mestrado em educação defendida na Universidade Federal de Sergipe (UFS), apresenta e discute parte dos resultados da pesquisa que investigou quais são os saberes construídos pelos professores nas práticas docentes da educação de pessoas jovens e adultas (EPJA). Para compreender sobre a experiência de ser professor na prática da sala de aula da EPJA, categoria em análise, realizamos uma pesquisa de natureza qualitativa, utilizando como instrumento para a coleta de dados entrevistas semiestruturadas, aplicadas com professores da rede municipal de ensino de Vitória da Conquista (BA), campo empírico do estudo. Vislumbramos que esses saberes se constituem em um repertório acumulado de conhecimentos do qual o professor lança mão a todo instante e em diversas situações para desenvolver o seu ofício docente.

PALAVRAS-CHAVE: Formação de Professores - Saberes Docentes - Práticas Pedagógicas

\begin{abstract}
This work, compositive part of the dissertation held in education at the Federal University of Sergipe (UFS), presents and discusses some of the results of research that investigates which are the knowledges built by teachers practicing education for young people and adults (EPJA). In order to understand about the experience of being a teacher in the practice classroom of EPJA, category in analisys, we conducted a qualitative research, using as a tool for data collection semi-structured interview, applied to teachers of the municipal teaching system in Vitória da Conquista (BA), empirical field of study. We see that this knowledge constitute an accumulated repertoire of knowledge from which the teacher makes use at all times and in different situations to develop his teaching profession.
\end{abstract}

KEYWORDS: Teacher Training - Teaching Knowledge - Pedagocical Practies 


\section{INTRODUÇÃO}

A educação ganha cada vez mais centralidade na sociedade contemporânea. Os avanços da microeletrônica, da biotecnologia e a globalização da economia e do mercado delineiam um novo padrão de produção e organização do mundo do trabalho, o que requer uma elevação do nível de qualificação do trabalhador e um novo perfil de professor para atender essas demandas.

Bennell (2001), ao pensar na formação docente no contexto dessas transformações, argumenta sobre a necessidade de pensar que cada sala de aula está inserida em um contexto sociocultural, que é plural, marcado pela diversidade de grupos e classes sociais, visões de mundo, valores, crenças, padrões de comportamentos etc., uma diversidade que esta refletida na sala de aula, realidade a qual o professor deve estar atento e que deve também nortear sua prática enquanto educador dessa realidade.

No entanto, a modalidade de Educação de Pessoas Jovens e Adultas (EPJA) no conjunto das políticas oficiais, mantém-se ocupando o lugar a ela reservado, de caráter secundário, excluído, marginalizado. Seja pela limitação do acesso à escola, seja pela inadequação das propostas ou pela ausência de formação de professores para atuar nessas turmas.

Apesar de a legislação regulamentar a formação de professores para atuar na modalidade de ensino, os trabalhos acadêmicos que se referem à temática analisados por Machado (2000) e que continuam como maior indicativo na atualidade, alerta para o fato de que a formação recebida pelos professores, normalmente realizadas por meio de treinamentos e cursos aligeirados, é insuficiente para atender as demandas da educação de jovens e adultos.

Tendo em vista que o saber é o centro da experiência escolar, postulamos que o entendimento das relações que os professores da EPJA estabelecem com o saber, o significado que atribuem aos saberes de sua prática pedagógica, assim como o modo como percebem sua relação com o ofício docente, podem trazer significativas contribuições para se pensar caminhos de formação docente para essa modalidade de ensino.

Neste trabalho, apresentamos algumas considerações sobre os saberes experienciais e as práticas dos professores na sala de aula da EPJA, relacionando a fala dos professores que atuam na modalidade como objeto de análise para nossas discussões. 


\section{OS SABERES EXPERIENCIAIS E A FORMAÇÃO DOS PROFESSORES DA EPJA: UM DIÁLOGO PERENE E PERTINENTE}

As discussões sobre os "saberes" popularizou-se no âmbito da literatura educacional a partir doa anos 90 e se tornou comum em diferentes áreas do conhecimento. Segundo Estrela (2005), há uma polissemia em torno da ideia do que são saberes, associando-se a expressões como: conhecimento, pensamento, teorias, crenças, concepções, perspectivas, etc.

$\mathrm{Na}$ literatura consultada para tecer este trabalho, observamos diferentes classificações desses saberes, na qual destacamos autores como Tardif (2005), Tardif e Lessard (2007), Gauthier et al. (2006) e Pimenta (2008).

No direcionamento teórico dessa pesquisa, optamos por tomar como referência os estudos de Tardif $(2005,2007)$ e Gauthier (2006), pelo fato de os seus estudos convergirem e proporem a valorização dos saberes experienciais como primordial para referendar as práticas que os professores produzem em suas ações pedagógicas.

Para Tardif (2005), a discussão sobre os saberes se iniciou, em âmbito internacional, a partir de 1980, dando origem às pesquisas que empregam teorias e métodos bem diversificados e propõem as mais diversas concepções a respeito dos saberes dos professores. Para esse autor, "não se pode no âmbito dos ofícios e das profissões falar do saber sem relacioná-lo com os condicionantes e com o contexto de trabalho: o saber é sempre o saber de alguém que trabalha alguma coisa no intuito de realizar um objetivo qualquer" (TARDIF, 2005, p.11).

Nessa mesma perspectiva, Charlot (2000) contribui para discussão ao afirmar que "o saber é uma relação, não há sujeito de saber e não há saber senão em uma certa relação com o mundo relação com o saber, consigo mesmo, com a linguagem e com os outros" (CHARLOT, 2000, p. 6364).

No campo específico da EPJA, poucas literaturas têm abordado sobre essa temática, principalmente no que se refere à formação de professores. Dentre as obras existentes, encontram-se os estudos de Fonseca (2002), relacionados à formação do professor de matemática para atuar na EPJA, que implicitamente discute os saberes necessários a esse professor, a partir de três dimensões inter-relacionadas entre si: a "intimidade com a matemática; sua sensibilidade para as especificidades da vida adulta; e sua consciência política” (FONSECA, 2002, p.55). Nesse sentido, Barcelos (2006) tece considerações sobre os saberes exigidos para o trabalho de professores na modalidade da EPJA, focando seu olhar para os alfabetizadores. 
Os estudos das obras desses autores apresentam que uma das possibilidades de se avançar nas atuais propostas de educação existentes para o ensino fundamental na modalidade da EPJA é tomar as experiências dos professores como ponto de partida para as discussões, debates e reflexões sobre a formação do professor. Entretanto, faz-se necessário um aprofundamento nos estudos referentes à literatura que trata dessa temática a fim de que as propostas de formação de professores possam contemplar não somente uma aprendizagem pela experiência, mas integrar a aprendizagem pela experiência à experiência existencial, como afirma Josso:

\begin{abstract}
a experiência existencial diz respeito ao todo da pessoa, diz respeito à sua identidade profunda, à maneira como ela vive como ser; enquanto a aprendizagem a partir da experiência, ou pela experiência, está relacionada apenas às transformações menores. Ainda que adquirir uma competência ou um saber-fazer instrumental ou pragmático possa mudar um certo número de coisas numa existência, não há verdadeiramente uma metamorfose do ser; há uma contribuição, por vezes, uma perda, mas não ocorre, na verdade, uma metamorfose. (JOSSO, 2004, p. 55).
\end{abstract}

Essa aprendizagem experiencial caracteriza a maneira pela qual os professores da educação de jovens e adultos vêm produzindo sua condição docente para essa modalidade de ensino.

Tendo em vista que o saber é o centro da experiência escolar, postulamos que o entendimento das relações que os professores da EPJA estabelecem com o saber, o significado que atribuem aos saberes de sua prática pedagógica, assim como o modo como percebem sua relação com o ofício docente, podem trazer significativas contribuições para se pensar caminhos de formação docente para essa modalidade de ensino.

Tardif (2005, p. 220), ao fazer referência a essa questão, destaca que os saberes da experiência são constituídos no exercício da prática cotidiana da profissão, fundamentados no trabalho e no conhecimento do meio. E acrescenta que, "são saberes que brotam da experiência e são por ela validados. Incorporam-se à vivência individual e coletiva (...) de saber fazer e de saber ser".

Diante da lacuna na formação específica para atuarem com jovens e adultos, as estratégias utilizadas pelos professores da EPJA são recorrentes as metodologias empregadas no ensino regular. Essa constatação nos remete a uma análise de como a formação de professores se sustenta nos programas de ensino das universidades e dos centros de formação de professores, evidentemente pautadas no modelo da racionalidade técnica, de caráter eminentemente conteudista e práticas limitadas ao final do curso com os estágios supervisionados. 
O distanciamento entre a formação teórica, ou seja, a formação através de conteúdos disciplinares que os professores recebem ao longo do curso e a prática realizada através de estágios, sendo na maior parte deles realizados ao final dos cursos, provocam um distanciamento entre o que é estudado e o que é refletido na ação pedagógica. É deste ponto de vista que Gauthier (2006) coloca que ao contrário de outros ofícios que desenvolvem um corpus de saberes, o ensino tarda a refletir sobre si mesmo.

A complexidade que a educação de jovens e adultos apresenta no bojo das relações educativas requer que a formação dos docentes que nela atuam seja ampla, na qual a experiência terá grande importância na gestão dos processos pedagógicos. Todavia, a esse professor são necessários outros conhecimentos adquiridos que não estão apenas em sua experiência.

Para atuar como docente, e mais especificamente na EPJA, onde os alunos apresentam um perfil pautado na "heterogeneidade, do confronto entre diferentes culturas e da relação entre diferenças culturais e diferenças nas capacidades e no desempenho intelectual" (OLIVEIRA, 2004, p. 23) é necessário ter em vista uma proposta de ensino planejada, onde as ações sejam metodologicamente corretas para o público que atende e que alcance a finalidade precípua do processo educativo que é a aprendizagem. Para que esse processo obtenha os resultados esperados não se trata apenas de construir sua prática através da experiência ou reduzir a ela a justificativa para o emprego desta ou daquela forma de ensinar.

A reflexão sobre sua própria prática permite ao professor melhor utilizar suas estratégias de ensino e a forma com a qual ela poderá ser empregada, como também outras questões que passaram a ser associadas às práticas docentes como ter vocação, cultura e experiência para o domínio de determinados conteúdos e consequentemente seu ensino são importantes. Contudo, apesar de integrarem o leque das atividades experienciais não podem ser tomadas isoladamente como condição preponderante para o ensino.

Para Gauthier:

O saber experiencial ocupa, portanto, um lugar muito importante no ensino [...], entretanto, esse saber experiencial não pode representar a totalidade do saber docente. Ele precisa ser alimentado, orientado por um conhecimento anterior mais formal que pode servir de apoio para interpretar os acontecimentos presentes e intervir em soluções novas (GAUTHIER, 2006, p. 37).

As situações concretas para o ensino na EPJA exigem que o professor mobilize uma diversidade de saberes para sustentarem suas práticas. A este respeito, Tardif (2005) e Gauthier et 
al. (2006) classificam os saberes docentes como um conjunto de conhecimentos que se constituem a partir de suas trajetórias de vida enquanto alunos, perpassa pela sua formação inicial e continuada e que ao longo do seu exercício profissional são refletidas, repensadas e validadas, dando origem a novos saberes.

Em Gauthier (2006), encontramos a classificação dos saberes dos professores divididas em seis categorias: saber disciplinar; saber curricular; saber das ciências da educação; saber da tradição pedagógica; saber experiencial e saber da ação pedagógica. O que para ele constitui como "uma espécie de reservatório de saberes no qual o professor se abastece para responder as exigências específicas de sua situação concreta de ensino" (GAUTHIER, 2006, p. 28).

Considera-se, assim, que o professor, em sua trajetória de vivência em sala de aula, constrói e desconstrói seus saberes conforme a necessidade de utilização dos mesmos e, do mesmo modo, conforme suas experiências de vida e seus percursos formativos e profissionais.

O saber experiencial faz parte do leque de ações e hábitos repetidos em determinados espaços e tempos, registrando-se como um repertório de saberes, tornado-se regras: "A experiência do professor não deixa de ser pessoal e, acima de tudo, privada" (GAUTHIER, 2006, p. 33). Esse saber é de foro íntimo do professor, é dele que emergem seus truques, suas maneiras, estratégias, seus domínios de suas ações: "O que limita o saber experiencial é exatamente o fato de que ele é feito de pressupostos e de argumentos que não são verificados por meio de métodos científicos" (Op. cit. p. 33).

Tardif (2005) categoriza os saberes docentes como sendo os saberes da formação profissional, os saberes disciplinares, curriculares e experienciais. Sobre este último, o autor afirma que “os saberes experienciais são formados de todos os demais, mas retraduzidos, 'polidos' e submetidos às certezas construídas na prática e na experiência” (Tardif, 2005, p. 54). Ressalta ainda que estes saberes possuem três objetos: primeiro: "as relações e interações que os professores estabelecem e desenvolvem com os demais atores no campo de sua prática"; segundo: "as diversas obrigações e normas às quais seu trabalho deve submeter-se"; terceiro: "a instituição enquanto meio organizado e composto de funções diversificadas".

Os saberes experienciais, de acordo com esse autor não são reconhecidos academicamente, são desvalorizados e estão num contexto de inferioridade em relação aos outros saberes.

Percebe-se que existe uma imposição cultural dos saberes da formação profissional, dos curriculares e dos disciplinares. Os professores, em geral, não participam na definição de tais saberes, ficando apenas no campo da execução. 
É a partir deste ponto que é preciso considerar a complexidade do cotidiano escolar enquanto o lugar privilegiado para a produção de saberes. É nesse espaço-tempo que, por exemplo, os saberes experienciais dos professores brotam, são mobilizados, construídos e ressignificados. O professor vai, aos poucos, construindo seu modo de ser e de se relacionar com seus pares, com os alunos, com os conteúdos que ministra, com os métodos e técnicas de ensino, de planejamento, avaliação, enfim, com toda a diversidade de situações que o ato educativo envolve.

\title{
A EXPERIÊNCIA DE SER PROFESSOR NA PRÁTICA DA SALA DE AULA DA EPJA
}

É no trabalho com a EPJA que os professores percebem que os conhecimentos adquiridos na formação inicial não são suficientes para desenvolver um ensino que atenda às necessidades dos alunos. Os professores percebem que precisam (re)significar os conhecimentos que já possuíam de sua formação universitária ou de experiências acumuladas como aluno ou como professor - para poder ensinar aos seus alunos. Portanto, seus saberes experienciais provêm de um processo de aprendizagem no qual os professores "retraduzem sua formação e a adaptam à profissão, eliminando o que lhes parece inutilmente abstrato ou sem relação com a realidade vivida e conservando o que pode servir-lhes de uma maneira ou de outra" (TARDIF, 2005, p. 53).

A EPJA como uma modalidade de ensino que ocupa pouco protagonismo nos sistemas de ensino ainda não é tratada como deveria nos cursos Licenciatura, através dos formadores de professores, de modo a formar professores comprometidos com a natureza que a modalidade apresenta. Se a preparação para atuar na EPJA estivesse sendo feita com maior compromisso por parte das instituições de ensino superior, por meio dos formadores, não teríamos tantos docentes afirmando que não sabem como começar seu trabalho na EPJA.

Vieira e Miranda (2000, p. 2) afirmam o seguinte:

\begin{abstract}
No âmbito específico da formação inicial de professores, em nível médio e superior, a inexistência de uma preocupação com esta área é evidenciada pela falta de disciplinas específicas de EJA que contemplem questões relacionadas a este campo. Como estes cursos são voltados para o trabalho com crianças/adolescentes, em idade e série apropriadas, estas ausências comprometem a formação de professores, dificultando o desenvolvimento de um trabalho de qualidade com estes grupos.
\end{abstract}

Considerando que diante da formação inicial não houve preparo para o ensino na EPJA, é natural que o professor só passe a se preocupar com a forma de ensinar os conteúdos aos seus 
alunos - jovens e adultos - quando entram em contato com eles, quando percebe que a forma tradicional de ensino não vai ser suficiente para educá-los.

Durante a pesquisa, percebemos nas entrevistas realizadas que os professores foram modificando suas concepções sobre os alunos da EPJA a partir do convívio com eles. Perceberam que seus alunos são diferenciados e que não podem ser tratados da mesma forma que os alunos do ensino regular.

Para uma das professoras entrevistadas, o que faz o professor mudar sua postura é a reflexão do cotidiano. Através da reflexão, o professor constrói essa diferença até mesmo na metodologia, na explicação, no objetivo. Segundo essa professora, o conteúdo é o mesmo, mas o tratamento é diferenciado. Isso porque a matriz curricular da EPJA obedece à mesma matriz do ensino fundamental, uma vez que a diferença está na forma de abordar e selecionar os conteúdos e isto vai depender do professor. Alguns professores seguem os conteúdos listados pela secretaria de educação, outros procuram selecioná-los de acordo com as reais necessidades de seus alunos.

Os professores entrevistados afirmaram que selecionam os conteúdos que vão ensinar de acordo com as características de seus alunos. A seleção dos conteúdos, feita por estes professores, mostra a preocupação que eles têm com a aprendizagem dos seus alunos. Eles perceberam, após inúmeros erros e acertos, que precisam ensinar o conteúdo "de outra maneira" para seus alunos como forma de garantir a aprendizagem deles.

Neste sentido, eles buscam promover uma aprendizagem significativa, ou seja, uma aprendizagem que procura resgatar os conhecimentos prévios dos alunos para a construção de novos saberes em sua aprendizagem.

A caracterização deste tipo de aprendizagem, segundo Moreira e Masini (1982), é a seguinte:

A aprendizagem significativa caracteriza-se pela interação entre o novo conhecimento e o conhecimento prévio. Nesse processo, que é não-literal e não arbitrário, o novo conhecimento adquire significados para o aprendiz e o conhecimento prévio fica mais rico, mais diferenciado, mais elaborado em termos de significados, e adquire mais estabilidade.

Essa compreensão da EPJA como uma modalidade de ensino que atende às mesmas "regras" do ensino fundamental e médio leva o professor a agir pedagogicamente de maneira semelhante e isso evidencia a ausência de um preparo para trabalhar na modalidade. O professor, sem orientação adequada, acaba utilizando as mesmas estratégias metodológicas trazidas do ensino "regular". 
Nesse processo de inserção dos professores nas turmas de EPJA, eles foram construindo saberes sobre como trabalhar com esses alunos, e que nós chamamos de saber da experiência de ser professor na EPJA. Tardif (2005, p. 39) diz que “os saberes experienciais, que são aqueles saberes que brotam da experiência e são por ela validados, incorporando experiência individual e coletiva sob a forma (...) de saber-fazer e de saber-ser". Este saber, portanto, foi adquirido na ação de ensinar a disciplina específica da formação do professor e no confronto com a realidade da EPJA.

A maneira como os professores concebem a EPJA está relacionada com suas experiências vividas nessa modalidade de ensino.

Os professores falam da EPJA como uma modalidade de ensino que foi criada para proporcionar escolarização às pessoas que não tiveram oportunidade de estudar e, também, no sentido de uma educação diferenciada, por se tratar de um grupo de alunos em condições diferenciadas das outras modalidades de ensino.

Assim diz um professor entrevistado: "não podemos ensinar o conteúdo direto sem fazer as devidas conexões com a realidade dos alunos". Isso porque a forma tradicional de ensinar não tem dado resultados positivos, quando se trata de alunos jovens e adultos.

Como nos diz Cavalcanti (1999, p. 2), esses "alunos adultos":

Acumulam experiências que vão ser fundamento e substrato de seu aprendizado futuro. Seus interesses pelo aprendizado se direcionam para o desenvolvimento das habilidades que utiliza no seu papel social, na sua profissão. Passam a esperar uma imediata aplicação prática do que aprendem, reduzindo seu interesse por conhecimentos a serem úteis num futuro distante.

Dessa forma, quando consideramos alunos adultos, não podemos tratar os conteúdos da mesma maneira que os tratamos com as crianças que, supostamente, devem aprender o que a sociedade espera que saibam em idade regular. Os adultos, de outra forma, supostamente, aprendem o que realmente precisam saber, ou seja, eles precisam de uma "aprendizagem para aplicação prática na vida diária" (CAVALCANTI, 1999, p. 3).

Se a prática do professor na EPJA é a mesma do ensino regular, ou seja, se na EPJA ele escolhe o que os alunos vão estudar, sem conhecer seus alunos e suas necessidades práticas, a tendência é que os alunos sejam novamente excluídos da escola, pois não encontram nela o ambiente propício à sua efetiva aprendizagem, ao que necessitam. Consoante Rodrigues (2006, p. 200) essa é "uma atitude claramente induzida pela incoerência das ações e falta de propósitos pedagógicos e de comprometimento social da escola". Percebemos que o saber da experiência 
apresentado pelos professores constitui sua identidade profissional, pois é obtido a partir de inúmeras reflexões que o professor faz sobre sua prática. Esse saber da experiência é o que faz o professor da EPJA construir seus saberes sobre ensinar na EPJA.

Esse saber é adquirido na prática, no exercício cotidiano de sua função e oferece ao professor algumas certezas sobre a sua prática em sala de aula, como as que são demonstradas pelos professores entrevistados em relação ao modo de ver e conceber os alunos da EPJA e ao modo como ensinam a eles. Essas "certezas" que o professor adquire na prática de sala de aula na EPJA são importantes para a sua constituição como professor por possuir uma dimensão formadora. Porém, Gauthier (1998, p. 24) nos chama atenção com relação ao saber da experiência ou experiencial que "não pode representar a totalidade do saber docente", pois ele "precisa ser alimentado, orientado por um conhecimento anterior mais formal que pode servir de apoio para interpretar os acontecimentos presentes e inventar soluções novas".

Para dar aulas para alunos de EPJA, ou de qualquer modalidade de ensino, consideramos que a experiência não deve ser a única responsável pela formação dos professores, como no caso dos nossos sujeitos de pesquisa. Para nós, considerar apenas a experiência como formativa para o professor pode acarretar prejuízos significativos aos alunos, principalmente aos alunos da EPJA.

Como nos diz Gauthier (1998, p. 24) Basear a aprendizagem de um ofício unicamente na experiência não deixa de ser uma
prática que custa extremamente caro, na medida em que isso significa deixar a cada docente
o cuidado de redescobrir por si mesmo as estratégias eficazes, com o perigo de acumular
sobre os alunos, durante um certo tempo, os efeitos negativos.

Sobre a afirmação de Gauthier, refletimos a respeito e nos questionamos: quantos de nossos alunos da EPJA já podem ter sido excluídos do sistema educacional por falta de formação específica de nossos professores pelas instituições de ensino superior?

Até que o professor perceba que precisa adequar sua prática às necessidades dos seus alunos, ele já pode ter perdido muitos desses alunos e ter contribuído para o aumento do número de exclusões escolares.

Vale atentar para o que diz Gauthier,

Advogar unicamente em favor da experiência é prejudicar a emergência do reconhecimento profissional dos professores, visto que se reconhece uma profissão principalmente pela posse de um saber específico formalizado e adquirido numa formação de tipo universitária (GAUTHIER, 1998, p. 24). 
Ademais, acreditamos que ter experiência, não significa dizer que o professor se desenvolveu profissionalmente e que sua prática pode ser formativa para futuros profissionais, pois acreditamos que, aliado à experiência, deve haver também, a constante reflexão sobre a prática.

Além de Gauthier, outros autores que discutem os saberes docentes, questionam a experiência como sendo responsável pela formação do professor.

Gonçalves (2000, p. 45), por exemplo, afirma que "não se aprende somente através da experiência, embora esta seja importante para o desenvolvimento profissional do professor, pois foi adquirida em decorrência de sua prática de sala de aula".

$\mathrm{O}$ autor propõe que os professores do ensino fundamental e médio retornem às universidades para que "o conhecimento oriundo de sua prática, que é singular a cada profissional), possa ser partilhado com futuros docentes e, quem sabe, teorizado e conceitualizado em parceria com os professores universitários" (CLARKE, 1994, apud GONÇALVES, 2000, p. 45).

Concordamos com as colocações dos autores no que tange à experiência, mas sabemos que a formação inicial não é capaz de abordar as variáveis que podem surgir no contexto da sala de aula, sendo por vezes necessário que o professor saia em busca de outros conhecimentos que o ajudem na sua atividade docente. A formação continuada dos professores poderia contribuir para que os saberes dos professores que trabalham na EPJA fossem apresentados para a comunidade acadêmica e, quem sabe, teorizado.

\section{ALGUMAS CONSIDERAÇÕES (IN) CONCLUSIVAS}

Para atuar na EPJA, os professores constroem conhecimentos práticos, desenvolvidos nas suas ações pedagógicas a partir da sua experiência, das habilidades adquiridas no cotidiano de atuação nessa modalidade de ensino.

Os professores são portadores de diversos saberes, que são construídos ao longo de sua trajetória docente. Esses saberes docentes são obtidos por meio da formação acadêmica que recebem e também no cotidiano de sua prática, com o trato na sua área específica de formação, com o currículo da escola e também com a experiência de atuação no magistério. Esses saberes se constituem em um repertório de conhecimentos do qual o professor lança mão a todo instante e em diversas situações para desenvolver o seu ofício docente.

Os professores que atuam na EPJA possuem esse repertório de conhecimentos, mas diferem dos professores que atuam em outras modalidades de ensino, visto que alguns elementos que fazem 
parte desse conjunto de conhecimento são limitados ou inexistentes em sua formação. É como se uma lacuna ficasse sem ser preenchida e, desse modo, esses professores produzem em seu trabalho a partir do que vivenciam na prática, construindo, portanto, saberes específicos para trabalhar na EPJA.

Pode-se apontar que, para os professores que atuam na EPJA, os saberes experienciais se constituem como um manancial, onde brotam os conhecimentos e atitudes que os professores desenvolvem a partir do seu cotidiano, de sua prática no trabalho diário com as turmas. Assim, tomando os saberes experienciais como categoria para análise dos dados, constatamos que os professores constroem e desenvolvem diversos saberes a partir da experiência. Os professores entrevistados, ao informarem que não obtiveram formação específica para lidar com as turmas da EPJA, afirmam que constroem seus saberes a partir da reflexão que fazem a respeito de suas ações cotidianas, construindo seus próprios saberes sobre como ensinar na EPJA. As certezas que são construídas pelos professores e que são validadas em suas práticas tornam-se legitimadas à medida que eles vão desenvolvendo sua trajetória profissional.

\section{REFERÊNCIAS}

BARCELOS, Valdo. Formação de professores para educação de jovens e adultos. Petrópolis:Vozes, 2006.

BENNELL, Ralph Ings. "A formação discursiva do professor e a (re) construção crítica do saber pedagógico". In. Movimento - Revista da Faculdade de Educação da Universidade Federal Fluminense, no . 4. Niterói, set. 2001.

CAVAlCANTI, R. A. Andragogia: a aprendizagem de adultos. Revista de Clínica Cirúrgica da Paraíba, João Pessoa, n. 6, ano 4, jul.1999.

CHARLOT, Bernard. Da relação com o saber: elementos para uma teoria. Trad. Bruno Magne. Porto Alegre: Artes Médicas Sul, 2000.

ESTRELA, Maria Tereza. Os saberes dos docentes vistos por eles próprios. Revista Portuguesa de Pedagogia, Coimbra, ano 39, n. 2, p. 433-450, 2005. 
FONSECA, Maria da Conceição F. R. Educação matemática de jovens e adultos: especificidades, desafios e contribuições. Belo Horizonte: Autêntica, 2002.

GAUTHIER, Clermont et al. Por uma teoria da Pedagogia. Ijuí: Unijuí, 1998.

GONÇALVES, T. O. Formação e desenvolvimento profissional de formadores: o caso dos professores de Matemática da UFPA. 2000, 206 f. Tese (Doutorado em Educação Matemática) Faculdade de Educação, Universidade Estadual de Campinas, Campinas, 2000.

JOSSO, Marie-Christine. Experiências de vida e formação. São Paulo: Cortez, 2004.

MACHADO, M. M. A prática e a formação de professores na EJA: uma análise de dissertações e teses produzidas no período de 1986 a 1998. In: Reunião anual da ANPED, 23, 2000, Associação Nacional de Pós-graduação e Pesquisa em Educação, Caxambu, 2000. (Edição eletrônica).

MOREIRA, M. A; MASINI, E. A. S. Aprendizagem significativa: a teoria da aprendizagem de David Ausubel. São Paulo: Ed. Moraes, 1982.

OLIVEIRA, I. A. Princípios pedagógicos na educação de jovens e adultos. Revista da Alfabetização Solidária, São Paulo, v. 4, n. 4, p. 59-74, ano 2004.

PIMENTA, S. G. Formação de professores: identidade e saberes da docência. In: PIMENTA, S. G. (Org.). Saberes pedagógicos e atividade docente. 6. ed. São Paulo: Cortez, 2008. p. 15-34.

RODRIGUES, A. M. S. A minha vida seria muito diferente se não fosse a matemática: o sentido e os significados do ensino de matemática em processos de exclusão e de inclusão escolar e social na Educação de Jovens e Adultos. 2006. Fls. 156. Dissertação (Mestrado em Matemática) Universidade Federal do Pará, Belém, 2006.

TARDIF, Maurice. Saberes docentes e formação profissional. Petrópolis, RJ: Vozes, 2005. 
TARDIF, Maurice, LESSARD, Claude. O trabalho docente hoje: elementos para um quadro de análise. In: .O trabalho docente: elementos para uma teoria da docência como profissão de interações humanas. 3Ed. Petrópolis: Vozes, 2007, p.15-54

VIEIRA, M. C; MIRANDA, H. T. Os significados da prática de ensino em educação de jovens e adultos na formação inicial de professores. Disponível em: <http://www.anped.org.br/24/p1803468048895.rtf>. Acesso em 21 jun. 2013.

${ }^{1}$ Doutorando em Educação, Universidade Federal de Minas Gerais, Faculdade de Educação (UFMG/FAE). Mestre em Educação, Universidade Federal de Sergipe (UFS). Professor Auxiliar do Departamento de Ciências Humanas, Educação e Linguagem da Universidade Estadual do Sudoeste da Bahia (UESB), campus de Itapetinga, Bahia. adenilsoncunha@uesb.edu.br

RECEBIDO EM: Setembro de 2016

APROVADO EM: Dezembro de 2016 